\title{
TAXA DE CRESCIMENTO DO ALMEIRÃO SUBMETIDO AO DÉFICIT DE ÁGUA NO SOLO
}

\author{
Rogério Rangel Rodrigues ${ }^{1}$ \\ Samuel Cola Pizetta ${ }^{2}$ \\ Nicolly Kalliliny Cavalcanti Silva ${ }^{3}$ \\ Wilian Rodrigues Ribeiro ${ }^{4}$ \\ Mário Euclides Pechara da Costa Jaeggi ${ }^{5}$ \\ Samuel Ferreira da Silva ${ }^{6}$ \\ Edvaldo Fialho dos Reis ${ }^{7}$
}

Resumo: Objetivou-se com esse trabalho avaliar a influencia do déficit hídrico sobre o desenvolvimento do almeirão (Cichorium intybus L.) cultivar folha amarela. Foi elaborado um experimento em casa de vegetação no Centro de Ciências Agrárias e Engenharias da Universidade Federal do Espírito Santo, em Alegre, ES. O experimento constitui-se de quatro tratamentos, sendo 80,60, 40 e 20\% da água disponível no solo, com quatro repetições, em um delineamento inteiramente casualizado. A época de avaliação foi aos 35 dias após início dos tratamentos. As variáveis avaliadas foram: taxa de biomassa fresca e seca da parte aérea, taxa do sistema radicular fresco e seco e taxa da área foliar. Os resultados demonstraram que os maiores valores, em taxa de crescimento, das variáveis avaliadas foram obtidos quando se utilizou até $80 \%$ da água disponível, diferindo significativamente dos demais tratamentos.

Palavras-chave: Cichorium intybus L.; Disponibilidade de água; Hortaliça.

\footnotetext{
${ }^{1}$ Recursos Hídricos em Sistemas Agrícolas/Universidade Federal de Lavras, Brasil. E-mail: rogeriorr7@hotmail.com.

${ }^{2}$ Recursos Hídricos em Sistemas Agrícolas/Universidade Federal de Lavras, Brasil. E-mail: scpizatta@hotmail.com.

${ }^{3}$ Recursos Hídricos em Sistemas Agrícolas/Universidade Federal de Lavras, Brasil. E-mail: nicollycavalcanti@yahoo.com.br.

${ }^{4}$ Agronomia/Centro de Ciências Agrárias e Engenharias, Brasil. E-mail: wilianrodrigues@msn.com.

${ }^{5}$ Produção Vegetal/Universidade Estadual Norte Fluminense, Brasil. E-mail: mariopechara@hotmail.com.

${ }^{6}$ Produção Vegetal/Centro de Ciências Agrárias e Engenharias, Brasil. E-mail: samuelfd.silva@yahoo.com.br.

${ }^{7}$ Professor/Centro de Ciências Agrárias e Engenharias, Brasil. E-mail: edreis@cca.ufes.com.br.
} 